\title{
Project-based Learning in Calculus on The Use of Maple Software Technology
}

\author{
Lina $\mathrm{Wu}^{1}$ and $\mathrm{Ye} \mathrm{Li}^{2}$ \\ 1. Department of Mathematics, Borough of Manhattan Community College The City University of New York, New York, NY 10007, \\ USA \\ 2. Department of Mathematics, Central Michigan University Mount Pleasant, MI 48859, USA
}

Received: March 25, 2017 / Accepted: April 22, 2017 / Published: May 25, 2017

\begin{abstract}
In this article, authors describe how to use the project-based learning (PBL) pedagogy to enhance students' Calculus learning based on the first author's experimental teaching experience. The "2014 BMCC Polar Art Calendar" project was completed by Calculus students at Borough of Manhattan Community College (BMCC) during the fall 2013 semester. Students were requested to apply graphs of polar equations to create computer-generated images with a variety of flower patterns by using the Maple technology in a math lab. At the end of this project, students were requested to submit and present their written reports to express their mathematical thinking. Authors also explain in details how to create projects compatible with textbook knowledge learning objectives, how to prepare scaffolding materials for students to use, how to utilize a math lab and to work with lab technicians in Maple Software, and how to design a rubric for project evaluations. Students' artwork created in the Polar Art Calendar are presented. Students' positive outcomes have proven a success of this project design as well as its execution as an example of PBL. Benefits to students and challenges to teachers on the use of PBL approach have been discussed at the end of this article.
\end{abstract}

Key words: artwork of flower patterns, graphs of polar equations, project-based learning, rubrics of project evaluations, the Maple technology, problem-solving skills

\section{Introduction}

The mathematical study, which consists of the study of mathematical symbols and geometric figures as well as formulas and theories, is too abstract for most of students to understand. In order to successfully solve mathematical problems, students need to improve their conceptual understanding ability by overcoming comprehension difficulties of mathematical terminologies and to apply theoretical knowledge to develop their problem-solving skills [1]. In the first stage, students must acquire cognitive ability in learning, which is an understanding ability of conceptual knowledge and theoretical knowledge. Lack of such ability will lead students to lose interest

Corresponding author: Lina $\mathrm{Wu}$, Associate Professor, research field: mathematics education and pure mathematics in differential geometry. E-mail: 1wu@bmcc.cuny.edu. in mathematics learning and to be bothered by mathematics anxiety. In the second stage, students must apply mathematical knowledge to develop their problem-solving skills in the context of real-world situations.

In order to strengthen connections between mathematical knowledge and its applications, mathematical educators normally would like to use word problems to show applications of book knowledge in real-life situations. The contrast between students' superficial "pure mathematical approach" to word problems in an ideal academic situation and students' deep "practical mathematical skill" to authentic problems in reality is documented and analyzed [2]. It showed that traditional word problems as mathematical models have very slim links to problems in the complicated real-life context. Without learning mathematics through solving 
problems, students have trouble in making connections between book knowledge and real-life situations. In an ideal school environment, students are only book smart and become good test-takers, while in reality, students have no idea how to make the best use of mathematical knowledge to better their life by solving challenging problems in their daily-life situations.

Educational researchers in mathematics have realized the significance of developing students' mathematical ability in a comprehensive way. Educators have tried their best to foster students' mathematical thinking, enhance students' conceptual understanding ability, develop students' problem-solving skills, improve students' mathematical communication skills in professional way, and others. Over the past decades, the reform of teaching has focused on all possible positive changes in the above directions such as an increase of students' interest as well as their conceptual understanding of disciplinary contents ([3][4][5]).

A variety of teaching pedagogies have been used in experimental stages. For example, modern computing technologies as digital demonstration tools in learning environments have been integrated in the traditional blackboard classroom lecturing [6]. Writing assignments as one approach of enhancing students' mathematical thinking has been used in teaching. Out-of-class educational activities in mathematical practice such as the Problem-Based Learning (PBL) approach have been merged into mathematics education. This pedagogy is derived from an idea of learning by doing. The PBL approach shifts a focus from lecturer-centered content delivery to student-centered activity engagement by increasing students' self-efficacy [7]. The PBL pedagogy as an inquiry-based instructional approach offers an innovative teaching method [8]. It reflects a learner-centered environment that concentrates on students' use of disciplinary knowledge, experiences, practices, and technologies to discover answers for real-world problems throughout projects ([9][10]).

In this article, authors describe how to use the PBL pedagogy to enhance students' Calculus learning based on the first author's experimental teaching experience. The "2014 BMCC Polar Art Calendar" project was completed by Calculus students at Borough of Manhattan Community College (BMCC) during the fall 2013 semester. Students were requested to apply graphs of polar equations to create computer-generated images with a variety of flower patterns by using the Maple technology in a math lab. At the end of this project, students were requested to submit their written reports and make presentations to express their mathematical thinking. Authors also explain in details how the project was designed to connect with Calculus knowledge, how to prepare scaffolding materials for students to use, how to utilize a math lab and to work with lab technicians in Maple Software, and how to design a rubric for project evaluations. Students' artwork created in the Polar Art Calendar are presented.

\section{Experimental Section}

\subsection{Project Narrative}

The learning objective of designing the "2014 BMCC Polar Art Calendar" project was to teach students Calculus and to show students how to apply their Calculus knowledge to create artwork by using graphing formulas in Maple Software. This innovative Calculus teaching was different from the traditional Calculus teaching. Applying practical use of Calculus knowledge in project learning rather than theoretical learning from textbook was a new teaching approach. The polar art calendar project has created interest and excitement to students in learning by doing.

The "2014 BMCC Polar Art Calendar" project requested students to use Calculus knowledge of graphing equations in polar coordinates to create artwork of flower patterns. Students were expected to use different types of polar equations to generate 
various flower diagrams with a combination of Rose Curves, Circles, Ellipses, Lemniscates, Cardioids with heart shapes, and Limacons with inner loops in their own way.

This was a group project. The class was divided into 6 groups, and each group consisted of 5 students. To obtain 12 images which could be used to create the poster of "2014 BMCC Polar Art Calendar", each group was responsible for designing 2 art images with different geometric patterns, shapes, compositions, colors, and sizes. Each image attached with its theme represents one month of a year.

This Calculus project was designed on the use of Maple Technology and was completed in a math lab. It comprised four consecutive phases in execution. First, all necessary theoretic Calculus knowledge regarding polar coordinates and polar equations was introduced to students in class. Second, all necessary technical knowledge in the Maple Software was taught to students in a math lab. Hands-on practice of using Maple Software commands enabled students to be familiar with the Maple software. Third, students started with creating their artwork. Fourth, after students completed computer-generated images, they were asked to compose written reports in which they had to express their thoughts and show their work.

\subsection{Project Scaffolding Materials}

Scaffolding materials including project guidelines and Maple handouts were provided for students to use as reference. In addition, students were able to use the website:

http://www.maplesoft.com/applications/view.aspx?
$\mathrm{SID}=4087 \&$ view $=\mathrm{html}$.

For example: guidelines that helped students to complete the group project were listed as follows

(1) What kind of flower diagrams do you want to create? What shapes and patterns are in your flower diagrams?

(2) What polar equations do you use to produce your expected flower images? How do you adjust parameter values in your selected polar equations?

(3) How do you compose multiple polar equations in one picture?

(4) What color or thickness would you like to choose?

(5) What Maple commands can help you to generate your artwork diagrams?

(6) What ideas, messages or themes are reflected in each of your artwork diagrams?

\subsection{Project Presentations and Writing Assignments}

Writing activities and PowerPoint presentations were assigned to students at the end of this project. Students in each group were required to submit only one written report to explain how they completed this project and what each participant had made in the group work. One student in each group was asked to make one PowerPoint presentation to show their group accomplishments.

\subsection{Rubric for Project Evaluation}

A rubric for this project evaluation was designed at the end of this project-based learning activity. Students' performance in each group was evaluated by the following rubric shown in Table I:

Table 1 Rubric for Project Evaluation of "2014 BMCC Polar Art Calendar".

\begin{tabular}{|c|c|c|c|c|c|}
\hline Checked Items/Rating by Points (pts) & $\begin{array}{l}\text { Excellent } \\
4 \text { pts }\end{array}$ & $\begin{array}{l}\text { Good } \\
3 \text { pts }\end{array}$ & $\begin{array}{l}\text { Fair } \\
2 \text { pts }\end{array}$ & $\begin{array}{l}\text { Poor } \\
1 \mathrm{pts}\end{array}$ & $\begin{array}{l}\text { Missing } \\
0 \text { pts }\end{array}$ \\
\hline \multicolumn{6}{|l|}{$\begin{array}{l}\text { Explanation on how to use different polar equations to generate } \\
\text { different curves }\end{array}$} \\
\hline \multicolumn{6}{|l|}{$\begin{array}{l}\text { Demonstration on how to apply Maple commands for the } \\
\text { computer-generated pictures }\end{array}$} \\
\hline \multicolumn{6}{|l|}{ Explanation on how to connect polar art diagrams with their themes } \\
\hline $\begin{array}{l}\text { Explanation of each participant's contribution in the group } \\
\text { accomplishments }\end{array}$ & & & & & \\
\hline
\end{tabular}




\section{Results and Discussion}

\subsection{Results of Students'Mathematical Thinking}

This project provided college mathematics instructors an effective way to assess students' graphing abilities in the polar coordinate system. Students' art design of polar curves in different shapes, such as Cardioids (heart-shaped), Rose Cures, Limacons with inner loops, Lemniscates, Circles, and others proved their full comprehension of polar equations and their practicable skill of using polar equations.

This project also gave students freedom and flexibility to express their creative ideas through a variety of their geometric artwork designs in their own way. In addition, students learned the use of Maple Software in this project. This approach of teaching brought excitement and motivation to students in learning.

Here is one example of students' work: Image of a Christmas flower generated from polar equations represents the month of December. This geometric artwork of a Christmas flower consists of 4 layers or 4 components from inside to outside. Each different layer is generated by one different polar equation in a specific color. Students selected an equation $r(t)=1.8+3.12 \cos (4.56 t)$ for $0<\mathrm{t}<31.25$ to produce the first inside layer as the basic shape of a Christmas flower in red. After that, an equation $r(t)=0.24+1.84 \cos (-3.96 t)$ for $0<\mathrm{t}<36.25$ was chosen to produce the second inside layer as a representation of a traditional Christmas bow in golden. The third equation $r(t)=-0.48-4.92 \sin (-5 t)$ for $0<t<31.25$ was used to generate the third inside layer as a symbolic Christmas star in green. The forth equation $r(t)=6+0.5 \sin (6.6 t)$ for $17.25<t<56.25$ was picked to generate the outside layer as a Christmas wreath in brown. Finally, students applied Maple commands to fill components in different colors with diverse thickness and displayed 4 components in one cohesive geometric picture by eliminating its axes and attaching it with a caption of the picture theme. Students used the Christmas flower as a symbol to express their holiday spirit in December. In a written report, students mentioned "We enjoyed the fact that math does not only involve numbers and equations but also can be artistic."

Students created many other distinctive images, such as Polar Rose, Lotus Flower, Blooming Violet, Mathematics Olympics and others.

\subsection{Results of "2014 BMCC Polar Art Calendar”}

The "2014 BMCC Polar Art Calendar" is presented below in Figure I:

\subsection{Discussion of Benefits to Students}

This PBL approach has ignited students' strong desire and enthusiasm in Calculus learning. First, working on this project, students were able to experience on how to connect mathematics and art. Students learned how to use mathematics theoretical knowledge to create something useful, beautiful, and meaningful in life. Second, students had an opportunity of using the Maple technology as an educational tool. Third, students acquired writing skills to communicate their mathematical work in a professional way. Students mentioned that it was their first time to use mathematical terminologies to express their thoughts. Fourth, by participating in group project, students learned to share their ideas with others. Collaboration and cooperation in group activities helped students to understand benefits of working together.

\subsection{Discussion of Challenges to Instructors}

The use of method could be a challenge for instructors. Instructors must tackle with these questions:

(1) How to design an appropriate project associated with textbook knowledge learning objectives?

(2) How to adapt scaffolding materials according with students' diverse backgrounds? 


\title{
BMCC POLAR ART CALENDAR 2014
}

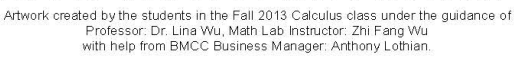
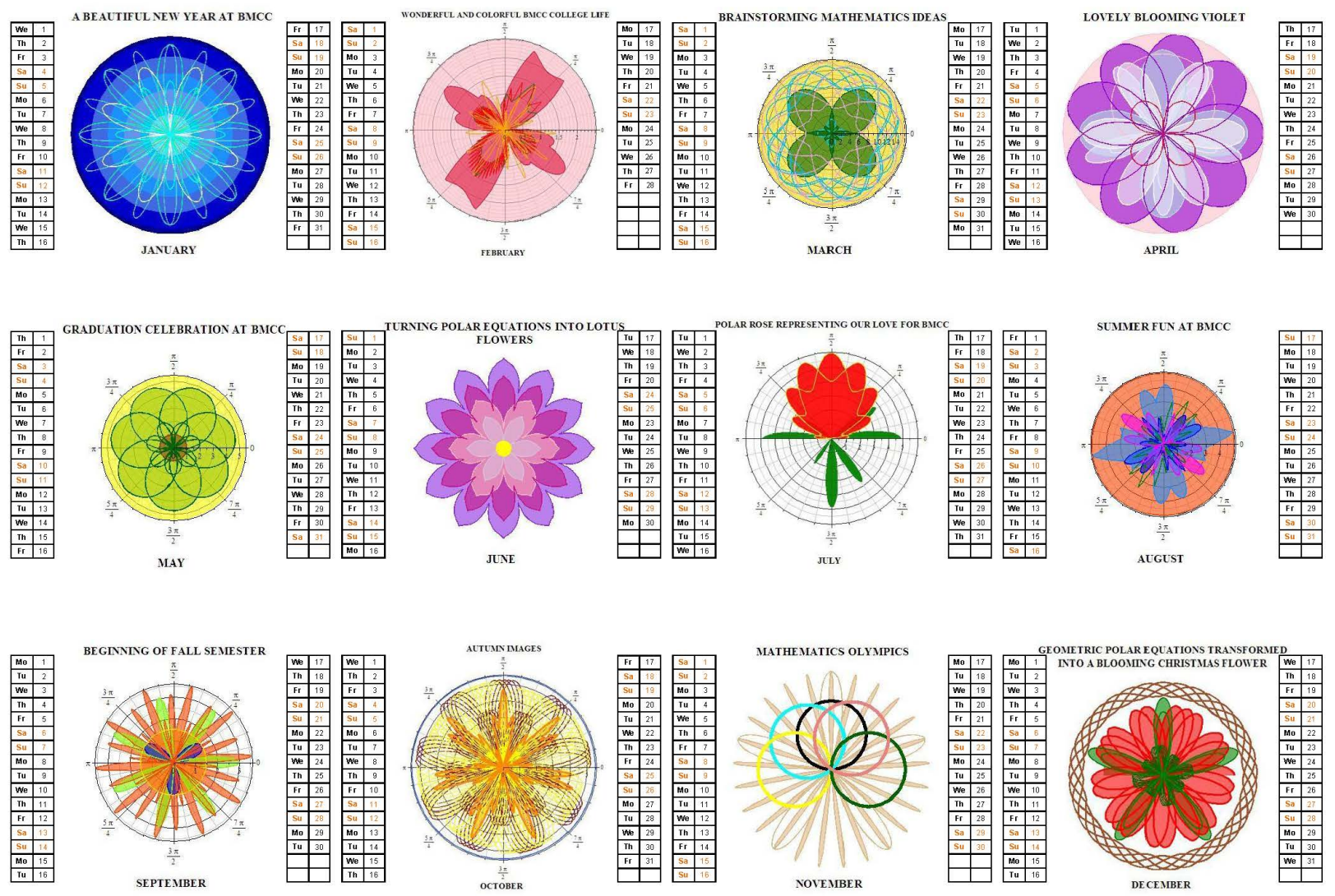

Fig. 12014 BMCC Polar Art Calendar.

(3) How to manage time to make this project realistic to be completed by students during the course study?

(4) How to make students obtain sufficient and necessary assistance from lab technicians in a math lab?

(5) How to design a professional rubric for project evaluation?

\section{Conclusions}

In the "2014 BMCC Polar Art Calendar" project, students have learned multiple skills, not only Calculus graphing skills, but also the basic use of Maple Software, teamwork, and communication skills in writing and speaking. Project outcomes have proved students' freedom and diversity in their creative thinking. Multiple skills with creative ideas as positive project outcomes will make students become competitive and qualified in the job market after college graduation. The eventual goal of college education is to develop students' adequate skills in their future career life.

The PBL approach is a very challenging teaching pedagogy. Applying a PBL method in teaching could confront teachers with some unexpected situations. Such situations might be to overcome the difficulty of project design, to convince students to participate, to control time management, to work with technicians, and to create rubrics of project evaluation as assessment. It could result in unpredictable outcomes beyond expectations. 
However, the PBL method has many benefits to facilitate students learning. By working on a realistic project for a structured group work, students will be expected to learn by discovering, questioning, practicing, and creating in their own way. This way of learning will be memorable. Just as students mentioned that they considered this experimental polar art project as a life-time experience. On the other hand, the PBL approach could be rewarding for teachers as well in many ways. One of rewarding outcomes could be to see students' enthusiasm engaged with the project by playing an active learning role. Another rewarding outcome could be to see students' creative work and to see how proud students feel themselves. In this polar art project, students were able to visualize the beauty of mathematics through their artwork. As students said, they became artistic in mathematical minds. Students' successful work with their positive feedbacks is a big reward to teachers.

Advantages of PBL have been well-recognized by educators in society. Recent research is investigated on how to reach full potential of the PBL pedagogy in the education system.

\section{Acknowledgment}

This "2014 BMCC Polar Art Calendar" project was funded by Enhanced Learning in Classroom at the Borough of Manhattan Community College (BMCC). Special thanks for the help from the BMCC Mathematics Technician: Zhifang $\mathrm{Wu}$ and also from the BMCC Business Manager: Anthony Lothian. This project was completed during the fall 2013 semester by: Josefine Kisch, Olga Rykova, Carolina Santelises, Destiny Rodriguez, An. Mikyoung, Deborah Miller, Jason Gooden, Alfonso Andino, Dilmurod Atabaev,
Christopher Mayol, Tivoy Cunningham, Fan Yang, Howie Shi, Christopher Calle, Robert Rodriguez, Kris Williams, Eric Buitron, Baoyan Tan, Karina Cheng, Yanling Feng, Zhaozhi Li, Alina Marsch, Luca Rossato, Haruka Washimi, Vijay Rampersaud, Marc Adrian Shieh, Steven Garcia, Ido Ayalon, Victor Akanbong, Dilshod Zaripov.

\section{References}

[1] B. Wong, L. Graham, M. Hoskyn, \& J. Berman, (Ed.). The ABCs of learning disabilities (2nd ed.). Elsevier Academic Press, Boston, 2008.

[2] L. Verschaffel, B. Greer, \& E. De Corte. Making sense of word problems. Lisse, The Netherlands, 2000.

[3] E. DeCorte, B. Greer, \& L. Verschaffel. Mathematics teaching and learning. In E. DeCorte, B. Greer \& L. Verschaffel (Eds.), Handbook of Educational Psychology. MacMillan, New York, 1996. pp. 491-549

[4] National Council of Teachers of Mathematics. An agenda for action. Reston, VA, 1980.

[5] W. H. Schmidt, C. McKnight, \& S. Raizen. A splintered vision: An investigation of U.S. science and mathematics education. Dordrecht: Kluwer, 1997.

[6] P. Maclaren. The new chalkboard: the role of digital pen technologies in tertiary mathematics teaching, Teaching Mathematics Applications 33 (1): 16-26, 2014.

[7] M. Llorens, E. Nevin, \& E. Mageean. Online resource platform for mathematics education. In Frontiers in Education Conference (FIE), 2014 IEEE (pp. 1-8). IEEE. 2014, October.

[8] J. S. Lee, S. Blackwell, J. Drake, \& K. A. Moran. Taking a Leap of Faith: Redefining Teaching and Learning in Higher Education Through Project-Based Learning. Interdisciplinary Journal of Problem-Based Learning, 8(2), 2014.

[9] J. S. Krajcik, \& P. Blumenfeld. Project-based learning. In R. K. Sawyer (Ed.), The Cambridge Handbook of the Learning Sciences. New York: Cambridge, 2006. pp. 317-333.

[10] T. Markham, J. Larmer, \& J. Ravitz. Project based learning handbook: A guide to standards-focused project based learning (2nd Ed.). Novato, CA: Buck Institute for Education, 2003. 